\title{
Quantitative Genotyping for the Astringency Locus in Hexaploid Persimmon Cultivars using Quantitative Real-time PCR
}

\author{
Takashi Akagi, Yumi Takeda, and Keizo Yonemori² \\ Laboratory of Pomology, Graduate School of Agriculture, Kyoto University, Sakyo-ku, \\ Kyoto 606-8502, Japan
}

\author{
Ayako Ikegami \\ Laboratory of Pomology, Department of Bioproduction Sciences, Ishikawa Prefectural University, \\ Nonoichi, Ishikawa 921-8836, Japan
}

\author{
Atsushi Kono and Masahiko Yamada ${ }^{1}$ \\ Grape and Persimmon Research Station, National Institute of Fruit Tree Science, Higashi-Hiroshima, \\ Hiroshima 739-2494, Japan \\ Shinya Kanzaki \\ Faculty of Agriculture, Kinki University, Nakamachi, Nara 631-8505, Japan
}

Additional index words. allele dosage, Diospyros kaki, polyploid plant

\begin{abstract}
Persimmon (Diospyros kaki Thunb.) is generally hexaploid, and a single $A S T$ locus controls the pollinationconstant non-astringency trait on each of six corresponding chromosomes. The pollination-constant non-astringent (PCNA) genotype is nulliplex and requires homozygous recessive alleles (ast) at the $A S T$ locus. There are several nonPCNA cultivars/selections that could be cross parents; however, the probability of yielding nulliplex offspring depends on the number of recessive alleles (ast). In genotyping for the $A S T$ locus in hexaploid persimmon, in contrast to the situation in diploid plants, we need to detect the $A S T / a$ st allele dosage; this cannot be detected by common codominant markers. In this study, we detected the allele dosage of $M_{a s t}$, which is a marker allele strongly linked to the ast allele among cultivars, by quantitative real-time polymerase chain reaction (qPCR) using three reference sites, actin (DkAct), anthocyanin reductase (DkANR), and L5R, whose sequences are conserved in the genome of persimmon cultivars. Based on the allele dosage of the $\mathbf{M}_{\text {ast }}, A S T /$ ast genotypes were estimated for 63 non-astringent cultivars/ selections, of which only five cultivars/selections were estimated to be simplex or duplex. The quantitative genotyping method using qPCR may be generally effective for polyploid plants.
\end{abstract}

Oriental persimmon, known simply as persimmon, is an important fruit crop in East Asia. Normally, persimmon accumulates abundant condensed tannins (proanthocyanidins) in fruit, which cause strong astringency. One of the main goals of the persimmon industry is to breed superior non-astringent cultivars. The most valuable and preferred cultivar is the pollinationconstant non-astringent phenotype, which does not accumulate high amounts of tannins (Akagi et al., 2009a; Yonemori et al., 2000).

The trait of natural astringency loss in pollination-constant non-astringent (PCNA) is controlled by a single gene (AST) (Yonemori et al., 2000). Previous reports have suggested that expression of the PCNA genotype requires the $A S T$ locus to be nulliplex. Indeed, plants that are heterozygous for the $A S T$ locus will express the astringency trait in fruit flesh (non-PCNA type; Ikeda et al., 1985; Yamada and Sato, 2002). Cultivated persimmon is hexaploid $(2 n=6 x=90)$ (Namikawa and Higashi, 1928; Tamura et al., 1998; Zhuang et al., 1990b), and Kanzaki et al. $(2001,2008)$ suggested the polysomic inheritance of the $A S T$ locus from the segregation ratio of AST-linked marker polymorphisms. Recently, Akagi et al. (2009b) determined the

Received for publication 26 Oct. 2009. Accepted for publication 14 Jan. 2010. ${ }^{1}$ Current address: NIFTS, Tsukuba, 305-8605, Japan.

${ }^{2}$ Corresponding author. E-mail: keizo@kais.kyoto-u.ac.jp. number of marker alleles linked to the $A S T$ locus using qPCR analysis and showed that six alleles are responsible for the astringency trait in persimmon, demonstrating that PCNA genotype is nulliplex at the $A S T$ locus.

In the actual breeding of PCNA-type persimmons, the hexaploid inheritance of the AST/ast allele restricts the breeder in intercrossing PCNA-type cultivars, selections, or both. When some non-PCNA-type cultivars were used as parents, PCNA offspring could only be obtained by a backcross of nonPCNA offspring obtained by a PCNA $\times$ non-PCNA cross to a PCNA genotype, and the percentage of PCNA-type offspring was low (Ikeda et al., 1985; Yamada and Sato, 2002). The ineffectiveness of such a cross is the main reason for the avoidance of nonPCNA genotypes in previous breeding programs. At present, the number of available PCNA-type cultivars is limited, and repeated crosses using these cultivars have resulted in inbreeding depression in progeny (Yamada et al., 1994). Hence, a good breeding strategy requires the inclusion of non-PCNA genotypes to widen the genetic pool and to avoid inbreeding depression.

In diploid plants, amplified fragment length polymorphisms (AFLPs), random amplified polymorphic DNAs (RAPDs), or simple sequence repeats (SSRs) are commonly used as dominant or codominant markers to detect polymorphisms (D'Surney et al., 2001). Dominant markers only detect the presence or absence of one of the two alleles. Codominant markers can 
detect the allelic state of both alleles, but are not usually used to quantify the allelic dosage in polyploid plants. In hexaploid persimmon, although a few restricted fragment length polymorphism (RFLP) or sequence-amplified characterized region (SCAR) markers linked to the AST/ast genes were identified by Kanzaki et al. (2008, 2009); these markers cannot detect the allelic state at the $A S T$ locus. In contrast to the situation in diploid plants, the relative ratio of two or more alleles must be determined to infer the genotype and the resulting phenotype of polyploid plants. Quantitative PCR has been used to measure chromosomal dosage for yeast (Bond et al., 2004) and to determine allele dosage in the tetraploid arabidopsis [Arabidopsis thaliana (L.) Heynh.] (Henry et al., 2006). In hexaploid persimmon, Akagi et al. (2009b) demonstrated the possibility of determining the AST/ast allele dosage by qPCR in a wellcharacterized selection. Information on the AST/ast allele dosage at the $A S T$ locus of a non-PCNA parent will greatly contribute to breeding superior PCNAs. If the ast allele of a non-PCNA parent is single dose (AAAAAa genotype) or double dose (AAAAaa), no hybridization can yield any PCNA offspring in crosses between non-PCNA and PCNA types because the ratio of the PCNA offspring depends on the ratio of a gamete whose genotype is "aaa," which is derived from a non-PCNA parent (Table 1). When the ast allele of a nonPCNA parent is more than triple dose (AAAaaa, AAaaaa, or Aaaaaa), it is possible that crosses between the non-PCNA and PCNA yield PCNA offspring at $\geq 5 \%$ under autoploid or autoalloploid inheritance (Table 1). To date, a few reports and recent unpublished results on some persimmon cultivars suggested the possibility that hexaploid persimmon is basically autohexaploid, but a few cultivars show autoallohexaploid and the details are not fully understood (Akagi et al., 2009b; Akagi and Yonemori, 2008; T. Akagi, unpublished data). The ambiguous inheritance mode is suggested in general polyploidy plants (Comai, 2005). For instance, allotetraploid sour cherry (Prunus cerasus L.) derived from hybridization between the diploid sweet cherry (Prunus avium L.) and the tetraploid ground cherry (Prunus fruticosa L.) shows a complex mode of inheritance in interspecific reciprocal crosses between sweet cherry and ground cherry (Hauck et al., 2006).

Kanzaki et al. (2001, 2008, 2009) identified a polymorphic marker linked to the AST locus in two breeding selections. The polymorphisms linked to the $A S T$ or ast alleles in this marker locus were well-characterized and showed four large-scale indels (Fig. 1; Kanzaki et al., 2008; T. Akagi, unpublished data). One of them, the retroposon-like $\approx 2.5$-kb insertion on this marker locus was strongly linked to the ast allele (Akagi et al., 2009b; Kanzaki

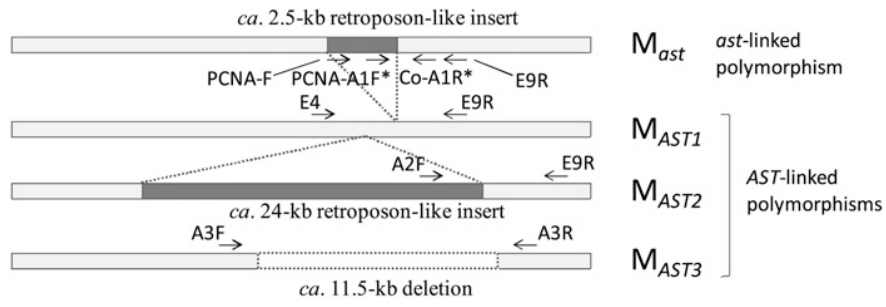

Fig. 1. Large-scale polymorphisms in $\mathrm{M}_{\text {ast }}$ and $\mathrm{M}_{A S T 1-3}$ (Kanzaki et al., 2009; T. Akagi, unpublished data), and the specific primer sets targeting each polymorphism shown in Table 3 (arrows indicate the primers). Primers with an asterisk were used in quantitative real-time PCR analysis for $\mathrm{M}_{\text {ast }}$ (Table 3).

et al., 2009). This marker allele is denoted as $\mathrm{M}_{\text {ast }}$, and the other three markers, which are linked to the $A S T$ allele, are denoted as $\mathrm{M}_{A S T 1-3}$ in this study (see Fig. 1). The objective of the present study is to demonstrate that qPCR analyses to determine the allele dosage of $\mathrm{M}_{\text {ast }}$ can be used to show the various genotypes of the AST/ast locus in the 60 non-PCNA cultivars. Information on the ast allele dosage or frequency among the cultivars will also provide an insight into the progress of ast allele accumulation. Furthermore, we will discuss further application of quantitative genotyping with qPCR not only for the $A S T$ locus, but also for other loci with polysomic inheritance.

\section{Materials and Methods}

IDENTIFICATION OF AN AST-LINKED MARKER ALLELE CONSERVED AMONG CULTIVARS. To confirm the validity of our hypothesis that $\mathrm{M}_{\text {ast }}$ is linked to the ast gene but not to the $A S T$ gene among cultivars, we tested whether non-PCNA cultivars have at least one marker allele for $\mathrm{M}_{A S T}$, while PCNA cultivars only have $\mathrm{M}_{\text {ast }}$. We used the 60 non-PCNA cultivars shown in Table 2 and the following 23 PCNA cultivars: Fujiwara-gosho, Fukuro-gosho, Fuyu, Gosho, Ikutomi, Izu, Izushi-ogosho, Jiro, Hana-gosho, Kanshu, Maekawa-jiro, Matsumotowase-fuyu, Midai, Mikado, Mushiroda-gosho, Ogosho, Okugosho, Suruga, Soshu, Taishu, Tenjin-gosho, Tokuda-gosho, and Yoshimotogosho.

Genomic DNA was isolated using the cetyltrimethylammonium bromide (CTAB) method (Doyle and Doyle, 1987) and was subjected to PCR analyses using the four PCR primers sets specific to the four marker alleles shown in Fig. 1. Briefly, we used primer sets (PCNA-F, E9R) for $\mathrm{M}_{a s t}$, $(\mathrm{E} 4, \mathrm{E} 9 \mathrm{R})$ for $\mathrm{M}_{A S T 1}$, (A2F, E9R) for $\mathrm{M}_{A S T 2}$, and (A3F, A3R) for $\mathrm{M}_{A S T 3}$ (see Fig. 1; Kanzaki et al., 2009; T. Akagi, unpublished data). Primer

Table 1. Each genotype at the AST locus in non-pollination-constant, nonastringent (non-PCNA) persimmon parents and corresponding ratio of the pollination-constant, nonastringent (PCNA) phenotype in $\mathrm{F}_{1}$ progeny, in crosses with PCNA types.

\begin{tabular}{|c|c|c|c|}
\hline \multirow[b]{2}{*}{$\begin{array}{l}\text { Hybridization (non-PCNA genotype }) \\
\times(\text { PCNA genotype })\end{array}$} & \multirow[b]{2}{*}{$\begin{array}{l}\text { ast allele dosage } \\
\text { of non-PCNA }\end{array}$} & \multicolumn{2}{|c|}{ Ratio of the PCNA phenotype in $\mathrm{F}_{1}(\%)^{\mathrm{z}}$} \\
\hline & & Autohexaploid & $\begin{array}{c}\text { Autoallohexaploid } \\
\text { (genotype in each karyotype of non-PCNA) }\end{array}$ \\
\hline AAAAAA $\times$ aaaaaa & & 0 & 0 \\
\hline AAAAaа $\times$ aаaаaа & Double & 0 & 0 \\
\hline AAAaаa $\times$ aаaаaа & Triple & 5 & 0 (AAAa/aa or Aaaa/AA), 8.3 (AAaa/Aa) \\
\hline AАаaаa $\times$ aаaаaа & Quadrivalent & 20 & 16.7 (AAaa/aa), 25 (Aaaa/Aa) \\
\hline
\end{tabular}

${ }^{\mathrm{Z}}$ In hexaploid persimmon cultivars, multivalent chromosome pairing is not exactly observed at meiosis (Zhuang et al., 1990a). We show the segregation ratio without consideration of random chromatid assortment or the possibility of double reduction. 
Table 2. Detection of the $\mathrm{M}_{\text {ast }}$ allele dosage and estimation of the quantitative genotype in the AST locus by quantitative real-time PCR analysis in non-pollination-constant nonastringent (non-PCNA) persimmon cultivars.

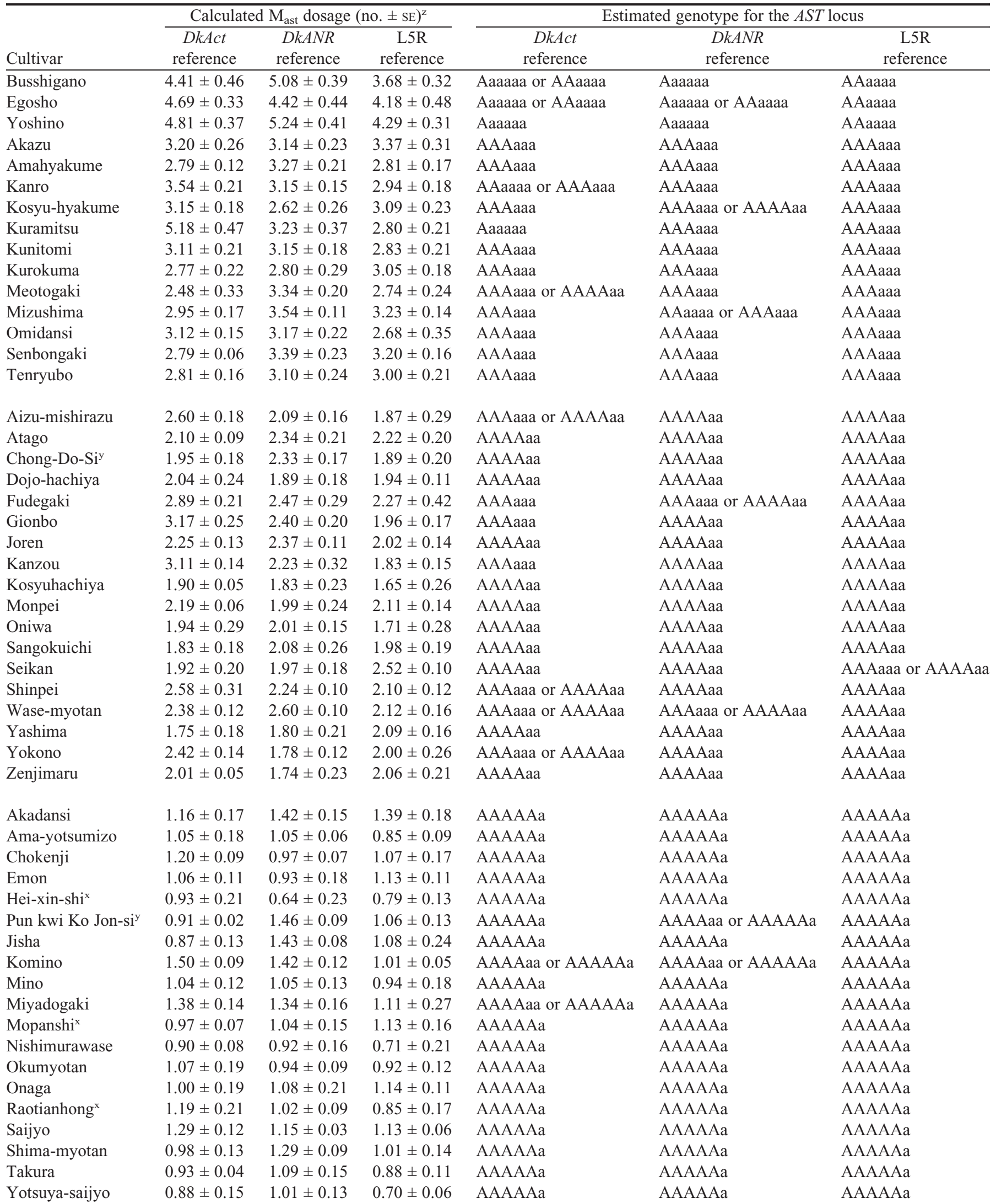

Continued next page 
Table 2. Continued.

\begin{tabular}{|c|c|c|c|c|c|c|}
\hline \multirow[b]{2}{*}{ Cultivar } & \multicolumn{3}{|c|}{ Calculated $\mathrm{M}_{\text {ast }}$ dosage (no. $\left.\pm \mathrm{sE}\right)^{\mathrm{z}}$} & \multicolumn{3}{|c|}{ Estimated genotype for the $A S T$ locus } \\
\hline & $\begin{array}{l}D k A c t \\
\text { reference }\end{array}$ & $\begin{array}{c}D k A N R \\
\text { reference }\end{array}$ & $\begin{array}{c}\mathrm{L} 5 \mathrm{R} \\
\text { reference }\end{array}$ & $\begin{array}{l}D k A c t \\
\text { reference }\end{array}$ & $\begin{array}{c}D k A N R \\
\text { reference }\end{array}$ & $\begin{array}{c}\mathrm{L} 5 \mathrm{R} \\
\text { reference }\end{array}$ \\
\hline Akagaki & $0.00 \pm 0.00$ & $0.01 \pm 0.00$ & $0.01 \pm 0.00$ & AAAAAA & AAAAAA & AAAAAA \\
\hline Dennai & $0.02 \pm 0.00$ & $0.01 \pm 0.00$ & $0.01 \pm 0.00$ & AAAAAA & AAAAAA & AAAAAA \\
\hline Hagakushi & $0.00 \pm 0.00$ & $0.00 \pm 0.00$ & $0.00 \pm 0.00$ & AAAAAA & AAAAAA & AAAAAA \\
\hline Luo-tian-tian-shi ${ }^{\mathrm{w}}$ & $0.01 \pm 0.00$ & $0.01 \pm 0.00$ & $0.01 \pm 0.00$ & AAAAAA & AAAAAA & AAAAAA \\
\hline Touhachi & $0.01 \pm 0.00$ & $0.01 \pm 0.00$ & $0.01 \pm 0.00$ & AAAAAA & AAAAAA & AAAAAA \\
\hline To-shi & $0.00 \pm 0.00$ & $0.01 \pm 0.00$ & $0.01 \pm 0.00$ & AAAAAA & AAAAAA & AAAAAA \\
\hline \multicolumn{7}{|l|}{ Selection } \\
\hline $275-13$ & $4.12 \pm 0.36$ & $3.89 \pm 0.12$ & $3.77 \pm 0.34$ & AAаaаa & AAaаaа & AAaаaа \\
\hline $170-26$ & $2.73 \pm 0.13$ & $2.88 \pm 0.26$ & $3.25 \pm 0.29$ & AAAaаa & AAAaaa & AAAaaa \\
\hline
\end{tabular}

${ }^{\mathrm{z}}$ Calculated $\mathrm{M}_{a s t}$ dosage is [(relative DNA dosage of $\left.\mathrm{M}_{a s t}\right) /($ relative DNA dosage of each reference site)] $\times 6$, based on the fact that 'Jiro' has six $\mathrm{M}_{\text {ast }}$ alleles in its genome. Relative DNA dosage was calculated from each $\mathrm{Ct}$ using the standard curves of the genomic DNA of 'Jiro' shown in Fig. 2.

y Korean cultivar.

${ }^{\mathrm{x}}$ Chinese cultivar.

w'Luo-tian-tian-shi' is a Chinese non-astringent cultivar whose genetic mechanism for the astringency loss is different from that of Japanese pollination-constant, non-astringent (PCNA) cultivars (Ikegami et al., 2006).

sequences are given in Table 3. We analyzed the sequences of the PCR products amplifying the $\mathrm{M}_{\text {ast }}$, which is the $2.5 \mathrm{-kb}$ inserted fragment ast-linked marker allele, using ExoSAP-IT (GE Healthcare Bio-Sciences, Piscataway, NJ) and CEQ8000 (version 7.0; Beckman Coulter, Tokyo).

EXAMINATION OF THE REFERENCE SITES FOR QPCR IN THE PERSIMMON GENOME. In qPCR analysis to determine the allele dose in the genome, a reference site where the number in the genome and sequences are conserved among the samples is necessary (Henry et al., 2006). Transposable sites, such as transposon- or retroposon-like, or high-copy genes are not suitable because the detected number of the sites could vary among persimmon cultivars. Considering the possibility that there are null or mutated alleles in a reference site locus, we performed three independent qPCR analyses using three reference sites in this study. For the qPCR reference site, we selected the genomic sequence of the two genes encoding actin (DkAct) (accession no. AB473616; Akagi et al., 2009a) and anthocyanidin reductase $(D k A N R)$ (accession no. AB195284; Akagi et al., 2009a; Ikegami et al., 2007), and one genomic marker locus named

Table 3. Primer information for general use in PCR analysis and for quantitative real-time PCR analysis. Each polymorphism of $\mathrm{M}_{\text {ast }}$ and $\mathrm{M}_{A S T 1-3}$ is shown in Fig. 1.

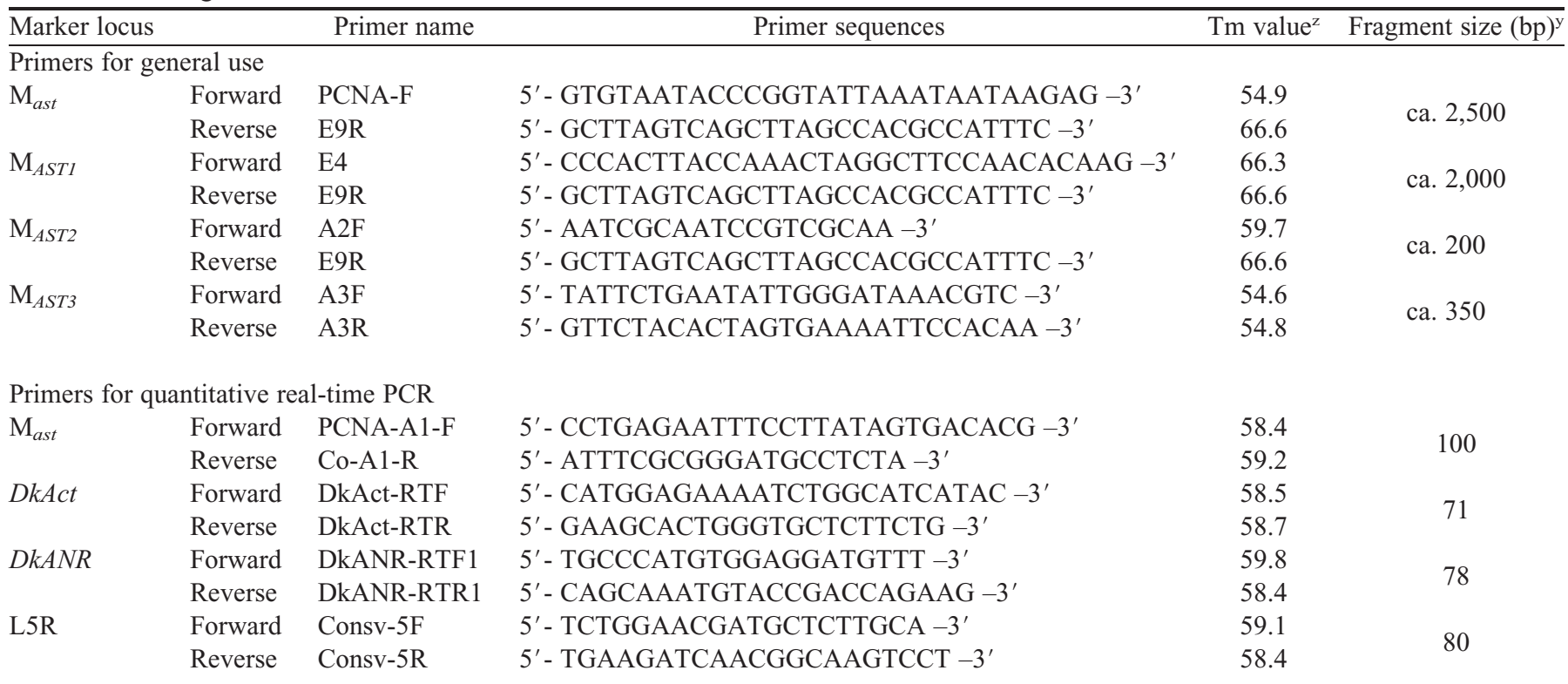

${ }^{\mathrm{z} T m}$ value was calculated using Primer Express Software (version 2.1; Applied Biosystems, Tokyo).

'Lengths of the amplified fragment in 'Kuramitsu' are shown. 
L5R (accession no. AB537429; T. Akagi, unpublished data), the sequence of which is conserved in the genus Diospyros $\mathrm{L}$. and is linked to the $A S T$ locus. To identify the conserved sequences of DkAct, DkANR, and L5R, their PCR products were directly analyzed using ExoSAP-IT and CEQ8000 (version 7.0). The conserved sequences were used as reference sites for qPCR. The primers for qPCR were designed using Primer Express Software (version 2.1; Applied Biosystems, Tokyo).

QPCR ANALYSIS FOR DETERMination OF THE $\mathbf{M}_{\text {ASt }}$ ALLELIC DOSAGE. We used the 60 non-PCNA cultivars shown in Table 2 to determine the $\mathrm{M}_{\text {ast }}$ allele dosage using qPCR analysis. In addition to these cultivars, we used three breeding selections, 170-26, 275-13, and 325-22, whose genotypes at the AST locus have been suggested from the segregation ratio of their offspring (Kanzaki et al., 2001, 2007, 2008; Yamada and Sato, 2002). DNA samples were thoroughly purified with phenol and chloroform extraction and were diluted to a concentration of $60 \mathrm{ng} \cdot \mu \mathrm{L}^{-1}$ to keep a constant amplification efficiency among samples in the following qPCR analysis. Samples were analyzed using an ABI PRISM 7900HT sequence detection system (Applied Biosystems) with the SYBR Green system using SYBR Premix Ex Taq (TaKaRa, Tokyo). All reactions were carried out in a total volume of $25 \mu \mathrm{L} /$ well, consisting of 12.5 $\mu \mathrm{L}$ of SYBR Premix, $9 \mu \mathrm{L}$ of sterilized distilled water, $1 \mu \mathrm{L}$ of each of forward and reverse detection primers $(5 \mu \mathrm{M}), 0.5 \mu \mathrm{L}$ of Rox dye, and $1 \mu \mathrm{L}$ of template DNA. All DNA samples were completely denatured at $95^{\circ} \mathrm{C}$ in a heating block for $10 \mathrm{~min}$ and were then cooled on ice before each reaction. The standard amplification protocol consisted of an initial denaturing step at $95^{\circ} \mathrm{C}$ for $30 \mathrm{~s}$, followed by 40 cycles at $95^{\circ} \mathrm{C}$ for $15 \mathrm{~s}, 57^{\circ} \mathrm{C}$ for $5 \mathrm{~s}$, and $72^{\circ} \mathrm{C}$ for $15 \mathrm{~s}$. The primer sequences used for detection of $\mathrm{M}_{\text {ast }}, D k A N R$, and L5R are shown in Table 3.

Standard curves for the $\mathrm{M}_{\text {ast }}$ and two reference sites were generated using two replications of eight serial 2 -fold dilutions of genomic DNA of 'Jiro' (PCNA), which has six $\mathrm{M}_{\text {ast }}$ in its genome (Akagi et al., 2009b). We set the maximum DNA concentration of the standard sample at approximately $120 \mathrm{ng} \cdot \mu \mathrm{L}^{-1}$. In the qPCR analysis, the average threshold cycle $(C t)$ was automatically determined by ABI PRISM $7900 \mathrm{HT}$ as the default state. $C t$ is defined as the point at which fluorescence rises appreciably above the background. For each measurement, independent standard curves were constructed and three replications of each sample were analyzed. The mean $C_{t}$ of three replications was used for each sample. The detected value of the $\mathrm{M}_{\text {ast }}$ relative to that of the reference site represents the $\mathrm{M}_{a s t}$ allelic dosage in the genome relative to that of the standard sample 'Jiro'.

\section{Results}

M $_{\text {AST }}$ IS STRONGLY LINKED TO THE AST GENE IN PERSIMMON CULTIVARS.
All 25 PCNA cultivars had only $\mathrm{M}_{\text {ast }}$ among the four marker alleles shown in Fig. 1 (data not shown). In contrast, all 60 nonPCNA cultivars had at least one of the other three marker alleles, $\mathrm{M}_{A S T 1}, \mathrm{M}_{A S T 2}$, and $\mathrm{M}_{A S T 3}$ putatively linked to the $A S T$ gene (Fig. 1), and most of them also had $\mathrm{M}_{\text {ast }}$. These results indicate that only $\mathrm{M}_{\text {ast }}$ is linked to the ast gene among the four alleles in the cultivars, and that non-PCNA cultivars possibly have many ast genes. The sequence analysis for $\mathrm{M}_{\text {ast }}$ showed single nucleotide polymorphisms among the cultivars. We designed the primer sets (forward: PCNA-A1F and reverse: Co-A1R) by amplifying the $\mathrm{M}_{\text {ast }}$ fragment specifically using the conserved sequences among the cultivars (Table 3 ).

QPCR ANALYSIS ESTIMATION OF THE AST ALLELE DOSAGE. We designed three specific primer sets for reference site of qPCR analysis, (DkActRTF and DkActRTR) for DkAct, (DkANRRTF1 and DkANR-RTR1) for DkANR, and (Consv-5F and Consv-5R) for L5R, using the conserved sequences among the cultivars (Table 3). In qPCR analysis, the amplification efficiency is an important factor affecting the results. The ideal value of the amplification efficiency is $100 \%$, which means the quantity of amplified fragments is doubled after one thermal cycle of PCR reaction. In this qPCR analysis, the amplification efficiencies of the DkAct, DkANR, L5R, and $\mathrm{M}_{a s t}$ markers were on average $95.1 \% \pm 1.2 \%, 96.4 \% \pm 0.6 \%, 96.6 \% \pm 1.3 \%$, and $97.6 \% \pm 2.7 \%$, respectively, and all standard curves were significantly linear $(P>0.995)$ (Fig. 2 , the standard curves generated from genomic DNA of 'Jiro'). These were valid enough to allow analysis of the allelic dosage in the genome.

The $\mathrm{M}_{\text {ast }}$ allelic dosage relative to that of the standard sample 'Jiro' was determined using qPCR analyses. We calculated the number of $\mathrm{M}_{\text {ast }}$ alleles in the genome based on the fact that 'Jiro' has six $\mathrm{M}_{\text {ast }}$ alleles (Akagi et al., 2009b). Our qPCR

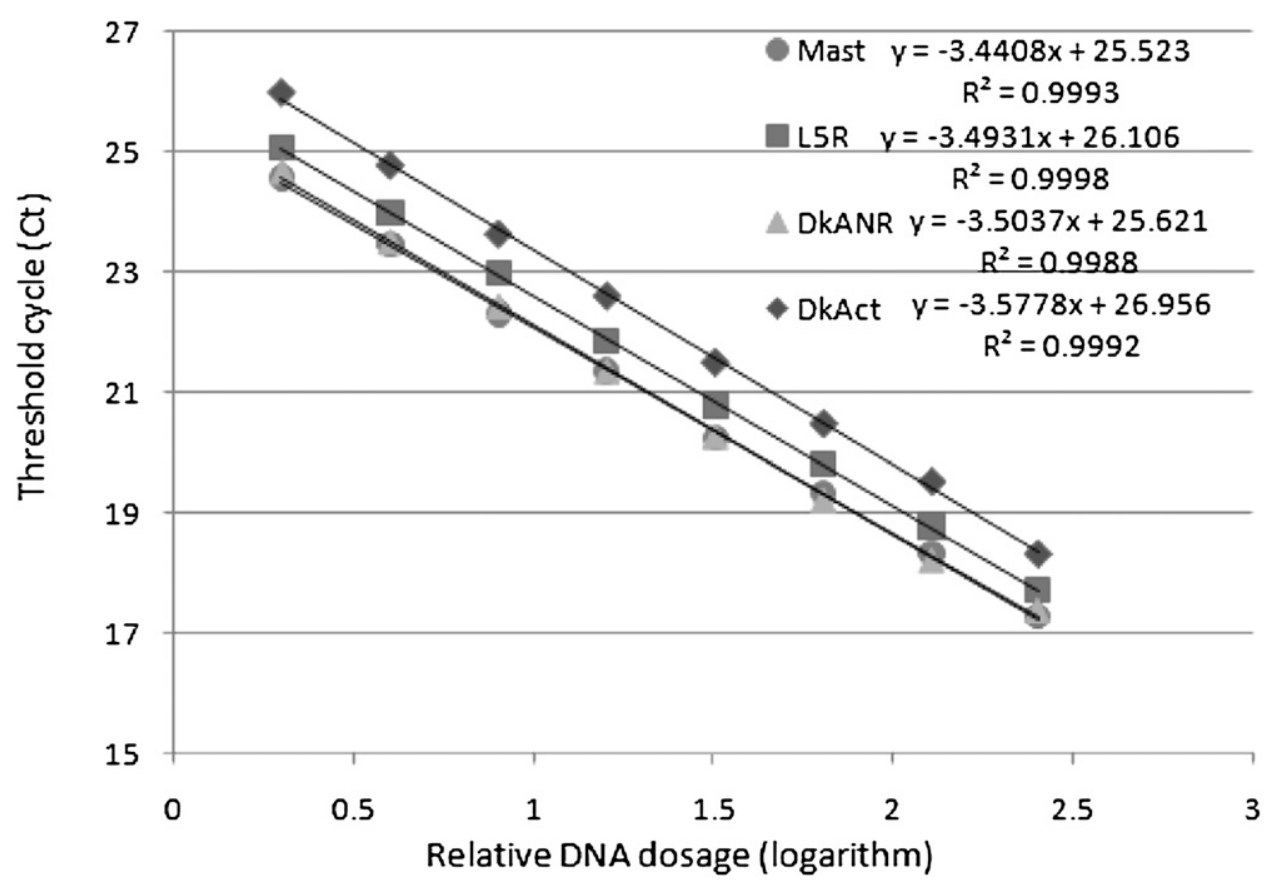

Fig. 2. Standard curves for $\mathrm{M}_{\text {ast }}$ (round points), L5R (square points), DkANR (triangular points), and DkAct (diamond-shaped points) in quantitative real-time PCR analyses using eight serial two-fold dilutions of the genomic DNA of 'Jiro' (PCNA). The x-axis indicates threshold cycle (Ct), automatically determined by $\mathrm{ABI} 7900 \mathrm{HT}$ as the default state. The $\mathrm{y}$-axis indicates relative DNA dosage expressed as logarithms. The minimum relative DNA dosage at the highest dilution of the genomic DNA of 'Jiro' was defined as " 1. ." 
results accurately showed the number of $\mathrm{M}_{\text {ast }}$ alleles in the genome and the estimated genotypes at the AST locus in the 60 non-PCNA cultivars and three breeding selections (Table 2). The number of $\mathrm{M}_{\text {ast }}$ or the estimated genotype at the $A S T$ locus was generally consistent in the three independent calculations using DkAct, DkANR, or L5R as reference sites. This result supported the validity of the three reference sites for qPCR analysis of the persimmon genome. Only 'Kuramitsu' showed strikingly different $\mathrm{M}_{\text {ast }}$ dosage or estimated genotypes, and a few cultivars had slighter inconsistencies, with the three reference sites (Table 2). This is possibly due to some mutated or null alleles in the reference sites that reduce amplification in qPCR analysis. To avoid this problem, several reference sites are needed for qPCR analysis when genotyping persimmon cultivars.

Most non-PCNA cultivars had zero to three $\mathrm{M}_{\text {ast }}$, indicating an estimated genotype of AAAAAA, AAAAAa, AAAAaa, or AAAaaa at the $A S T$ locus (Table 2). The ratio of each estimated genotype at the $A S T$ locus among the 60 non-PCNA cultivars was as follows: 14.3\% (AAAAAA), 33.9\% (AAAAAa), 32.1\% (AAAAaa), 21.4\% (AAAaaa), and 5.4\% (AAaaaa or Aaaaa). The average of the $\mathrm{M}_{\text {ast }}$ allele dosage in a cultivar ranged from 1.72 to 1.77 . The estimated ast allelic frequency in the 60 cultivars was 29\%. Previous reports by Kanzaki et al. (2001, 2007, 2008) and Yamada and Sato (2002) suggested the AST/ ast genotypes of three breeding selections, 170-26, 275-13, and 325-22, from the segregation ratio of their offspring in the AST/ast (non-PCNA/PCNA) phenotypes. The dominant AST allele dosage of 170-26, 275-13, and 325-22 was suggested to be triple, double, and single dose, which indicate the AST/ast genotypes of AAAaaa, AAaaaa, and Aaaaaa, respectively. Our results showed that the estimated genotypes of 170-26, 275-13, and 325-22 are AAAaaa, AAaaaa, and Aaaaaa, respectively (Table 2), which are consistent with the results from the segregation analyses.

The AST/ast genotypes of 'Busshigano', 'Egosho', and 'Yoshino' were estimated to be Aaaaaa or AAaaaa (Table 2). In addition, 12 cultivars were estimated to have the triple-dose ast alleles (Table 2). At present, when a non-PCNA-type cultivar is used as a parent, PCNA offspring are obtained only by backcrossing the second generation, and the ratio of obtainable PCNA offspring is low (Ikeda et al., 1985; Yamada and Sato, 2002). However, our results suggest that some non-PCNA cultivars have a triple dose or more of the ast allele, meaning that crosses between them and a PCNA genotype would yield about 5\% to 50\% PCNA offspring under autohexaploid inheritance in a single generation.

\section{Discussion}

EXAMinAtion AND APPLICATION OF THE METHODOLOGY OF QPCR ANALYSIS FOR QUANTITATIVE GENOTYPING. Quantitative PCR to determine the gene or allele dosage was first used in the field of medicine (Ochshorn et al., 2006; Zimmermann et al., 2002) because changes in gene dosage cause significant damage to humans. Plant molecular biologists applied qPCR to determine the copy number of a transgene (Song et al., 2002) and to study karyotypes in arabidopsis (Henry et al., 2006). Henry et al. (2006) also proposed the novel strategy of genotyping for polyploid plants by quantitative analysis of allele dosage with qPCR. In our study, we applied this qPCR methodology to quantitative genotyping of the AST locus in several hexaploid persimmon cultivars. We accurately estimated the AST/ast genotype in almost all of the non-PCNA cultivars studied (Table 2).

However, our methodology for the quantitative AST/ast genotyping by qPCR still has a few problems. There were significant calculation errors in the measurements for cultivars that had a high ast allele dosage, such as Busshigano, Egosho, and Yoshino (Table 2, see SE). This is presumably due to the methodology of the qPCR analysis. When we compare the single-dose allele to double-dose allele by qPCR analysis, a 2 -fold difference is detected. When we compare the quadrivalentdose allele to pentavalent-dose allele, the ability to detect a 1.25 -fold difference is required. That is difficult and accompanies some errors in analysis because the detection of a 1.25fold difference means detection of a difference of about 0.322 $\left(=\log _{2} 1.25\right)$ cycles in real-time PCR analysis. A solution to this problem is to measure the number of marker alleles linked to the dominant $A S T$ gene because the more the recessive ast alleles are, the less the dominant $A S T$ alleles are in a genome. The detection of dominant and recessive alleles by qPCR will enable exact quantitative genotyping. However, in this study, we could not detect the dosage of $\mathrm{M}_{A S T}$ linked to the dominant $A S T$ allele because of the $\mathrm{M}_{A S T}$ polymorphisms shown in Fig. 1 . It is necessary to identify the conserved sequences linked to the $A S T$ allele or the $A S T$ gene itself to detect the dosage of the $A S T$ allele.

Quantitative genotyping by qPCR is effective in two respects, marker-assisted selection (MAS) and the genome mapping of polyploid plants. Quantitative genotyping by qPCR could contribute to MAS, especially for recessive traits in polyploid plants, such as the PCNA trait in persimmon, because the probability of obtaining nulliplex offspring greatly depends on the dosage of the recessive allele in the parents, an example of which is shown in Table 1 . We can also apply quantitative genotyping for loci whose allele balances involve quantitative traits in polyploid plants. Furthermore, genome-wide mapping of autohexaploid sweetpotato [Ipomoea batatas (L.) Lam.] has been reported recently (Cervantes-Flores et al., 2008a, 2008b; Kriegner et al., 2003). In these reports, the segregation ratio of offspring was modeled corresponding to quantitative genotype in each marker locus. Allele dosage or quantitative genotyping in each marker locus is important in this mapping. Hence, the qPCR approach for quantitative genotyping would be possibly applicable to this genome-wide mapping in autoploid plants. To date, a number of maps in well-characterized autopolyploid plants, such as sugarcane (Saccharum L.) or potato (Solanum tuberosum L.), have been developed using various approaches (e.g., interspecific crossing or comparative genomic analysis) (Garcia et al., 2006; Le Cunff et al., 2008; Ming et al., 2002), but genome-wide mapping of other many autopolyploid plants has not progressed yet mainly due to various technical difficulties derived from genomic complexity (Henry et al., 2006; Luo et al., 2006). The qPCR method for quantitative genotyping could be one of the simple solutions to this problem and would facilitate the genome mapping in many autopolyploid plants, including persimmon.

Transition OF AST ALLELIC FREQUENCY POSSIBLy ELUCIDATES THE ORIGIN OF PCNA TYPE. Our results suggested that quantitative AST/ast genotypes vary among the 60 non-PCNA cultivars (Table 2). The ast allelic frequency was $29 \%$. The cultivar with the highest ast allele dosage, Yoshino, originates from the same area as a PCNA cultivar, Gosho. In addition, 
'Egosho' and 'Busshigano', which also contain a high ast allele dosage (Table 2), originate in areas near to that of 'Gosho' or other major PCNA cultivars such as Fuyu. The existence of 'Gosho' is first mentioned in the seventeenth century (Kikuchi, 1948), and 'Gosho' was the only PCNA cultivar to be grown over a wide area 200 years ago (Yamada, 2005). This suggests that 'Gosho' is the original PCNA, as inferred by Yamada (2005), and that the accumulation of the ast allele and the resultant generation of the PCNA phenotype occurred around the region where 'Gosho' arose. There are more than 1500 cultivars of persimmon in China, Japan, Korea, and Europe (Wang et al., 1997; Yamada, 2005). The ast allelic frequency is presumed to differ among countries. Therefore, a detailed detection of the ast allelic frequency among the cultivar groups in these areas could contribute to understanding how the ast allele has accumulated.

\section{Literature Cited}

Akagi, T., A. Ikegami, Y. Suzuki, J. Yoshida, M. Yamada, A. Sato, and K. Yonemori. 2009a. Expression balances of structural genes in shikimate and flavonoid biosynthesis cause a difference in proanthocyanidin accumulation in persimmon (Diospyros kaki Thunb.) fruit. Planta 230:899-915.

Akagi, T. and K. Yonemori. 2008. Analysis of heterogeneous inheritance mode of the astringency trait of persimmon fruit by the typing of molecular markers. Hort Res. (Japan) 7(supplement 2):130 (Abstr.). (In Japanese).

Akagi, T., S. Kanzaki, M. Gao, R. Tao, D.E. Parfitt, and K. Yonemori. 2009b. Quantitative real-time PCR to determine allele number for the astringency locus by analysis of a linked marker in Diosypros kaki Thunb. Tree Genet. Genomes 5:483-492.

Bond, U., C. Neal, D. Donnelly, and T.C. James. 2004. Aneuploidy and copy number breakpoints in the genome of large yeasts mapped by microarray hybridization. Curr. Genet. 45:360-370.

Cervantes-Flores, J.C., G.C. Yencho, A. Kriegner, K.V. Pecota, M.A. Faulk, R.O.M. Mwanga, and B. Sosinski. 2008a. Development of a genetic linkage map and identification of homologous linkage groups in sweetpotato using multiple-dose AFLP markers. Mol. Breed. 21:511-532.

Cervantes-Flores, J.C., G.C. Yencho, K.V. Pecota, B. Sosinski, and R.O.M. Mwanga. 2008b. Detection of quantitative trait loci and inheritance of root-knot nematode resistance in sweetpotato. J. Amer. Soc. Hort. Sci. 133:844-851.

Comai, L. 2005. The advantages and disadvantages of being polyploid. Nat. Genet. 6:836-846.

Doyle, J.I. and J.L. Doyle. 1987. A rapid DNA isolation procedure for small quantities or fresh leaf tissue of woody plants. Biotechniques 19:11-15.

D'Surney, S.J., L.R. Shugart, and C.W. Theodorakis. 2001. Genetic markers and genotyping methodologies: An overview. Ecotoxicology 10:201-204.

Garcia, A.A.F., E.A. Kido, A.N. Meza, H.M.B. Souza, L.R. Pinto, M.M. Pastina, C.S. Leite, J.A.G. da Silva, E.C. Ulian, A. Figueira, and A.P. Souza. 2006. Development of an integrated genetic map of a sugarcane (Saccharum spp.) commercial cross, based on a maximumlikelihood approach for estimation of linkage and linkage phases. Theor. Appl. Genet. 112:298-314.

Hauck, N.R., H. Yamane, R. Tao, and A.F. Iezzoni. 2006. Accumulation of nonfunctional S-haplotypes results in the breakdown of gametophytic self-incompatibility in tetraploid Prunus. Genetics 172:1191-1198.

Henry, I.M., B.P. Dilkes, and L. Comai. 2006. Molecular karyotyping and aneuploidy detection in Arabidopsis thaliana using quantitative fluorescent polymerase chain reaction. Plant J. 48:307-319.

Ikegami, A., S. Eguchi, A. Kitajima, K. Inoue, and K. Yonemori. 2007. Identification of genes involved in proanthocyanidin bio- synthesis of persimmon (Diospyros kaki) fruit. Plant Sci. 172:10371047.

Ikegami, A., S. Eguchi, A. Sato, M. Yamada, A. Kitajima, N. Mitani, and K. Yonemori. 2006. Segregations of astringent progenies in the $\mathrm{F}_{1}$ populations derived from crosses between a Chinese pollinationconstant non-astringent (PCNA) 'Luo Tian Tian Shi', and Japanese PCNA and pollination-constant, astringent (PCA) cultivars. HortScience 41:561-563.

Ikeda, I., M. Yamada, A. Kurihara, and T. Nishida. 1985. Inheritance of astringency in japanese persimmon. J. Jpn. Soc. Hort. Sci. 54:3945 (in Japanese with English summary).

Kanzaki, S., A. Sato, M. Yamada, K. Yonemori, and A. Sugiura. 2001. Identification of molecular markers linked to the trait of natural astringency loss japanese persimmon (Diospyros kaki) fruit. J. Amer. Soc. Hort. Sci. 126:51-55.

Kanzaki, S., A. Sato, M. Yamada, N. Utsunomiya, A. Kitajima, A. Ikegami, and K. Yonemori. 2008. RFLP markers for the selection of pollination-constant and non-astringent (PCNA)-type persimmon and examination of the inheritance mode of the markers. J. Jpn. Soc. Hort. Sci. 77:28-32.

Kanzaki, S., M. Yamada, A. Sato, N. Mitani, N. Utsunomiya, and K. Yonemori. 2009. Conversion of RFLP markers for the selection of pollination-constant and non-astringent type persimmon (Diospyros kaki Thunb.) into PCR-based markers. J. Jpn. Soc. Hort. Sci. 78: 68-73.

Kanzaki, S., M. Kimura, M. Yamada, N. Mitani, T. Akagi, N. Utsunomiya, and K. Yonemori. 2007. Segregation of fruit astringency type and selection of PCNA offspring using RFLP marker in the $\mathrm{BC}_{1}$ progeny derived from 'Kurokuma' persimmon. Hort Res. (Japan) 6(supplement 1):356 (Abstr.). (In Japanese).

Kikuchi, A. 1948. Pomology: Part I. Yokendo, Tokyo. (in Japanese). Kriegner, A., J.C. Cervantes, K. Burg, R.O.M. Mwanga, and D.P. Zhang. 2003. A genetic linkage map of sweetpotato [Ipomoea batatas (L.) Lam.] based on AFLP markers. Mol. Breed. 11:169185.

Le Cunff, L., O. Garsmeur, L.M. Raboin, J. Pauquet, H. Telismart, A. Selvi, L. Grivet, R. Philippe, D. Begum, M. Deu, L. Costet, R. Wing, J.C. Glaszmann, and A. D'Hont. 2008. Diploid/polyploid syntenic shuttle mapping and haplotype-specific chromosome walking toward a rust resistance gene (Brul) in highly polyploid sugarcane $(2 \mathrm{n} \sim 12 \mathrm{x} \sim 115)$. Genetics 180:649-660.

Luo, Z.W., Z. Zhang, L. Leach, R.M. Zhang, J.E. Bradshaw, and M.J. Kearsey. 2006. Constructing genetic linkage maps under a tetrasomic model. Genetics 172:2635-2645.

Ming, R., Y.W. Wang, X. Draye, P.H. Moore, J.E. Irvine, and A.H. Paterson. 2002. Molecular dissection of complex traits in autopolyploids: Mapping QTLs affecting sugar yield and related traits in sugarcane. Theor. Appl. Genet. 105:332-345.

Namikawa, I. and M. Higashi. 1928. On the number of chromosomes in Diospyros kaki L. f. and Diospyros lotus L. Bot. Mag. (Tokyo) 42:436-438.

Ochshorn, Y., A. Bar-Shira, A. Jonish, and Y. Yaron. 2006. Rapid prenatal diagnosis of aneuploidy for chromosome 21, 18, 13, and $\mathrm{X}$ by quantitative fluorescence polymerase chain reaction. Fetal Diagn. Ther. 21:326-331.

Song, P., C. Cai, M. Skokut, B. Kosegi, and J. Petolino. 2002. Quantitative real-time PCR as a screening tool for estimating transgene copy number in WHISKERSTM-derived transgenic maize. Plant Cell Rep. 20:948-954.

Tamura, M., R. Tao, K. Yonemori, N. Utsunomiya, and A. Sugiura. 1998. Ploidy level and genome size of several Diospyros species. J. Jpn. Soc. Hort. Sci. 67:306-312.

Wang, R., Y. Yang, and G. Li. 1997. Chinese persimmon germplasm resources. Acta Hort. 436:43-50.

Yamada, M. 2005. Persimmon genetic resources and breeding in Japan. Acta Hort. 685:51-64.

Yamada, M. and A. Sato. 2002. Segregation for fruit astringency type in progenies derived from crosses of 'Nishimura-wase' $\times$ pollination 
constant non-astringent genotypes in oriental persimmon (Diospyros kaki Thunb). Scientia Hort. 92:107-111.

Yamada, M., H. Yamane, and K. Ukai. 1994. Genetic analysis of japanese persimmon fruit weight. J. Amer. Soc. Hort. Sci. 119:1298-1302.

Yonemori, K., A. Sugiura, and M. Yamada. 2000. Persimmon genetics and breeding. Plant Breed. Rev. 19:191-225.

Zhuang, D.H., A. Kitajima, and M. Ishida. 1990a. Chromosome number of japanese persimmon cv. 'Miyazakitanenashi' and 'Watar- isawa', and meiotic division in cv. 'Zenjimaru'. J. Jpn. Soc. Hort. Sci. 59(supplement 1):106-107 (Abstr.). (In Japanese).

Zhuang, D.H., A. Kitajima, M. Ishida, and Y. Sobajima. 1990 b. Chromosome numbers of Diospyros kaki cultivars. J. Jpn. Soc. Hort. Sci. 59:289-297. (In Japanese with English summary).

Zimmermann, B., W. Holzgreve, F. Wenzel, and S. Hahn. 2002. Novel real-time quantitative PCR Test for Trisomy 21. Clin. Chem. 48:362-363. 